\title{
Neutron irradiation hardening across ITER diverter tungsten armour
}

\author{
D. Terentyev ${ }^{1 *}$, C. Yin ${ }^{1,2}$, A. Dubinko ${ }^{1}$, C.C. Chang ${ }^{1,2}$, J.H. You ${ }^{3}$ \\ ${ }^{1}$ SCK CEN, Nuclear Materials Science Institute, Boeretang 200, B-2400 Mol, Belgium \\ ${ }^{2}$ Université Catholique de Louvain, Institute of Mechanics, Materials and Civil Engineering, \\ 1348 Louvain-la-Neuve, Belgium \\ ${ }^{3}$ Max Planck Institute for Plasma Physics, Boltzmann Str. 2, 85748 Garching, Germany
}

\begin{abstract}
In this work, we have performed neutron irradiation and sub-sequent hardness measurements on a series of tungsten grades to screen the irradiation-induced hardness as a function of irradiation temperature reaching up to $1200^{\circ} \mathrm{C}$. The selected irradiation temperatures were chosen by performing temperature analysis of the expected irradiation temperature on tungsten monoblock during the steady state operation in ITER, where $1200^{\circ} \mathrm{C}$ corresponds to the surface temperature at $10 \mathrm{MW} / \mathrm{m}^{2}$ flux density expected during normal operational conditions. The applied neutron fluence and flux (using BR2 material test reactor, up to $1 \mathrm{dpa}$ ) is representative of ITER irradiation conditions except the neutron spectrum. However, the measures were taken to reduce the thermal neutron flux to limit the transmutation closer to the fusion conditions. The irradiation-induced hardness measured in single crystal after irradiation at $600-800^{\circ} \mathrm{C}$ agrees very well with the earlier data reported after HFIR irradiation experiments. The new irradiation data obtained in the temperature range $900-1200^{\circ} \mathrm{C}$ show that even at one third melting point the neutron exposure raises the hardness by 40 to $70 \%$, depending on the selected grade. Screening measurements by transmission electron microscopy, applied to clarify the origin of the hardening at $1200^{\circ} \mathrm{C}$, have proven the presence of the dislocation loops and high density of voids. The presence of those defects should imply the reduction of thermal conductivity, fracture toughness as well as alteration of hydrogen isotope permeation and trapping.
\end{abstract}

Keywords: Tungsten; Neutron irradiation; ITER

\section{Introduction}

Tungsten (W) is selected for armour application in fusion devices (i.e. JET, ITER, and candidate for DEMO applications [1-3]) due to its ability to withstand high heat loads, prolonged interaction with plasma and acceptable nuclear activation [4]. However, the development of the components withstanding the $14 \mathrm{MeV}$ neutron exposure during the nuclear operation phase requires further exploration of tungsten properties, in particular investigation of neutron irradiation effects [5] and its impact on mechanical properties .

Even in the non-irradiated state, the ductile-to-brittle transition temperature (DBTT) of $\mathrm{W}$ is rather high, i.e., $300-400{ }^{\circ} \mathrm{C}$, depending on the fabrication route, post treatment and test type (see e.g. [6-8]), but it can be reduced given a dedicated mechanical treatment (see e.g. [911]). Upon operation in a nuclear fusion environment, the DBTT raises further due to the irradiation-induced lattice defects and transmutation producing gas bubbles limiting the ability of material for plastic deformation [12]. Although W primarily serves as armor material, it also imposes a structural function in the current ITER divertor design $[4,13]$. Correspondingly, the

\footnotetext{
${ }^{*}$ Corresponding author, email: dterenty@sckcen.be
} 
design of the divertor components should account for the change of the mechanical properties after the neutron irradiation. The modification of the microstructure due to the neutron irradiation in the hot part (i.e. close to the plasma surface) may result in the reduction of thermal conductivity as well as may alter the trapping of tritium and helium coming from the plasma [12]. Hence, the assessment of the irradiation effects is required across a large span of the operational temperatures. The plasma facing components of the divertor will experience the largest heat loads [13] and therefore the operational temperature of tungsten varies there from around 300 up to $1200^{\circ} \mathrm{C}$ on steady state regime at $10 \mathrm{MW} / \mathrm{m}^{2}$ power load, as was assessed for the ITER and DEMO divertor target in [14-16].

From the view point of the currently available knowledge, the risk of brittle failure of tungsten is believed to realize at the operational temperature below $800{ }^{\circ} \mathrm{C}$, see review made by EU material assessment group [17]. Indeed, the information on the irradiation effects in tungsten above $800{ }^{\circ} \mathrm{C}$ is scarce [18]. It is known that the peak of neutron irradiation swelling, i.e. formation of voids and gas bubbles, realizes at $800{ }^{\circ} \mathrm{C}$ [19]. However, the measurable swelling remains up to at least $1200{ }^{\circ} \mathrm{C}$. Recent works involving positron annihilation spectroscopy (PAS) measurements indeed confirm the presence of cavities in tungsten irradiated at $1200{ }^{\circ} \mathrm{C}$ [20]. The transmission electron microscopy (TEM) study by Arakawa et al. [21] has shown that dislocation loops and voids introduced by ion irradiation at $500{ }^{\circ} \mathrm{C}$ are stable against thermal annealing up to at least $1100{ }^{\circ} \mathrm{C}$, although a big fraction of the loops is recovered around $900{ }^{\circ} \mathrm{C}$. The void recovery takes place between $1100{ }^{\circ} \mathrm{C}$ and $1400{ }^{\circ} \mathrm{C}$ implying that their formation under irradiation is indeed expected at $1200^{\circ} \mathrm{C}$.

Hardness measurements are relatively quick and simple tests (i.e. budget-affordable characterization means of mechanical properties). By now, several works have characterized the irradiation hardening in single crystal and polycrystalline $\mathrm{W}$ (and $\mathrm{W}$ alloys) by means of the Vickers micro-hardness measurements. The micro-hardness is known to correlate with the yield stress [22-24]. Various neutron irradiation campaigns in the high flux isotope reactor (HFIR) in the temperature range $80-830^{\circ} \mathrm{C}$ have shown that the radiation-induced hardening $(\mathrm{RIH})$ does not saturate up to $1 \mathrm{dpa}$ [25-28]. Neutron irradiation recently performed in the Belgian Reactor 2 (BR2) on single crystal $\mathrm{W}$ at low dose (0.12 dpa) has shown a particular temperature dependence of the irradiation hardening in the range $600-1200{ }^{\circ} \mathrm{C}$, where the maximum of $\mathrm{RIH}$ is found at $800{ }^{\circ} \mathrm{C}$ [20], while an overall increase of the hardness agrees well with the earlier reported data. However, the information on the hardness response in the middle to high irradiation dose and at high irradiation temperature is currently missing.

The present work aims at exploring the effect of neutron irradiation on the microhardness measured in several tungsten grades after the exposure at low, medium and high temperature to a fluence comparable to the end of design life of ITER (i.e. 1 dpa). Two sets of grades have been irradiated in the present study, namely: (i) single crystal, commercially pure bar being reference material for EU fusion programme, commercially pure tungsten sheet; and (ii) $\mathrm{W}$ reinforced with $\mathrm{ZrC}$ particles with proven reduced DBTT [29], the EU reference $\mathrm{W}$ in the recrystallized state and commercially pure $\mathrm{W}$ provided by Japanese supplier. The first set was irradiated at four different doses and four temperatures $\left(600-1200^{\circ} \mathrm{C}\right)$, while the second set was irradiated only at one dose, close to $1 \mathrm{dpa}$. The irradiation below $600{ }^{\circ} \mathrm{C}$ was not considered in this study because $\mathrm{W}$ is known to exhibit severe embrittlement after the irradiation in the low temperature range [30]. The main objective of this work is to characterize the radiation-induced hardening in the above mentioned grades after low, medium and high temperature neutron exposure; analyse the link between the RIH, initial microstructure and irradiation temperature; and finally to perform screening TEM analysis to investigate the microstructure at the lowest and highest irradiation temperatures applied here. 


\section{Experimental techniques and substantiation of selected experimental conditions and materials}

The two sets of samples were irradiated in this study. Set 1 contained the materials with a strongly contrasting microstructure i.e. single crystal, stress-relived commercial pure tungsten (ITER specification grade supplied by EU provider) and heavily deformed sheet which exhibits a certain ductility even at RT. The investigation of the reference hardness of materials in Set 1 is presented in Ref.[31]. The target irradiation doses for the samples of Set 1 were 0.1, 0.2, 0.6 and $1 \mathrm{dpa}$. The target irradiation temperature was $600,800,900$ and $1200^{\circ} \mathrm{C}$. Set 2 contained the materials chosen because of the technological needs such as: recrystallized (at $1600^{\circ} \mathrm{C}$ for 1 hour) ITER specification grade supplied by Plansee (Austria), ITER specification grade supplied by Japanese provider (A.L.M.T.) and fine-structured $\mathrm{W}-\mathrm{ZrC}$ alloys which is known to have superior mechanical properties in the low temperature range. The target irradiation dose for the samples of Set 2 was $\sim 1$ dpa to be achieved at three irradiation temperatures, namely: 600,1000 and $1200^{\circ} \mathrm{C}$.

The basic information about the fabrication route of the studied materials is summarized below together with the acronyms used throughout the paper to refer to those materials:

IGP: Commercially pure ITER specification tungsten grade produced by Plansee, Austria. The material is supplied as a rod (with square cross-section $36 \mathrm{~mm}$ x $36 \mathrm{~mm}$ ) which was hammered on both sides, more info on the properties of this material can be found in [32]. In addition to the as-fabricated stress-relived state, the IGP samples, exposed to thermal annealing at $1600^{\circ} \mathrm{C}$ for 1 hour to induce the recrystallization expected to occur in the upper part of the monoblock, have been irradiated. The recrystallized IGP material will be referred to as IGP-RX.

ALMT: Commercially pure ITER specification tungsten grade produced by A.L.M.T., Japan. The samples were cut from the mono-blocks. The material has microstructure and chemical composition very similar to what is reported in Ref. [33].

SC: Single crystal W(100) rod of $99.99 \%$ purity of $12 \mathrm{~mm}$ diameter was supplied from MaTeck, Germany. This material has been already investigated in our earlier work, which reported the results of PAS at low irradiation dose [20].

HDK: Commercially pure tungsten which is doped with potassium and rolled to a thickness of $1 \mathrm{~mm}$. This fabrication route was exploited to fabricate room-temperature ductile $\mathrm{W}-\mathrm{Cu}$ laminates, developed by Karlsruhe Institute of Technology, Germany [34].

WZC: particle reinforced tungsten containing $0.5 \mathrm{wt} \% \mathrm{ZrC}$, provided in a form of plate by the Institute of Solid State Physics, China [35]. The end product is a rolled plate which passed thermo-mechanical treatment (TMT) in order to get grain refinement and controlled distribution of $\mathrm{ZrC}$ precipitates. The first study of the neutron irradiation effects in this material has been conducted in Ref. [36].

The inverse pole figures of these tungsten grades are shown in Fig. 1 with the indication of longitudinal direction (LD) and transversal direction (TD). Table 1 provides the composition, and medium equivalent diameter (D50) together with $10 \%$ and $90 \%$ equivalent diameter (D10, D90) of the grains, which are defined as the equivalent grain sizes that are larger than $50 \%$, $10 \%$, and $90 \%$ of the total grains, respectively. This information can help a reader to appreciate the width of the grain size distribution. Beside the EBSD-deduced information, for some of the 
materials a detailed TEM study of the reference microstructure was performed in our recent studies [37, 38]. Dislocation density reported elsewhere for the IGP, IGP_RX, W0.5ZrC and HDK materials is provided in Table 1.
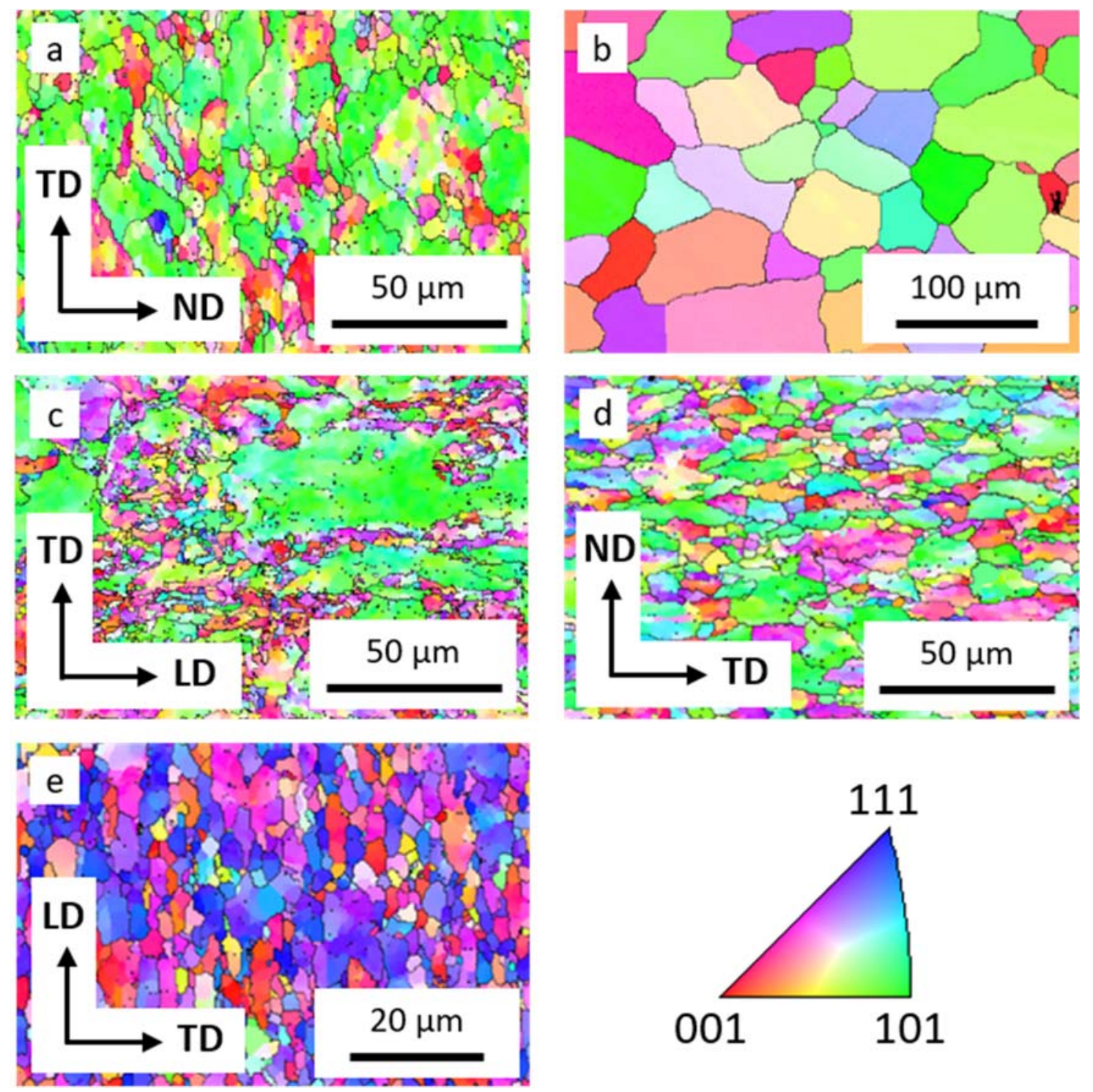

Figure 1. Inverse pole figure of different tungsten grades: (a) IGP [39]; (b) IGP-RX [39]; (c) HDK [40]; (d) ALMT [39]; (e) W0.5ZrC [41].

Table 1. Chemical composition, grain size and dislocation density of different tungsten grades. The compositions of the commercial grades are provided by the manufacturer. Last coloumn reports the Vickers hardness values.

\begin{tabular}{|c|c|c|c|c|c|c|}
\hline Material & $\begin{array}{c}\text { Major composition } \\
\text { (by weight) }\end{array}$ & $\begin{array}{c}\mathrm{D} 10 \\
(\mu \mathrm{m})\end{array}$ & $\mathrm{D} 50(\mu \mathrm{m})$ & $\begin{array}{c}\mathrm{D} 90 \\
(\mu \mathrm{m})\end{array}$ & $\begin{array}{c}\text { Dislocation } \\
\text { density } \\
\left(\mathrm{m}^{-2}\right)\end{array}$ & $\begin{array}{c}\text { VH0.2 } \\
{[\mathrm{GPa}]}\end{array}$ \\
\hline SC & Pure W (99.999\%) & \multicolumn{2}{|c|}{ Defect free as revealed by TEM } & - & 3.7 \\
\hline IGP & $\begin{array}{c}\text { Pure W }(>99.97 \\
\%)\end{array}$ & $\begin{array}{c}4.77^{[39]} \\
\%\end{array}$ & $15.78^{[39]}$ & $31.45^{[39]}$ & $4.5 \times 10^{12}$ & 4.54 \\
\hline
\end{tabular}




\begin{tabular}{|c|c|c|c|c|c|c|}
\hline IGP-RX & $\begin{array}{c}\text { Pure W (>99.97 } \\
\%)\end{array}$ & $31.67^{[39]}$ & $60.38^{[39]}$ & $\begin{array}{c}108.40 \\
{[39]}\end{array}$ & $2.0 \times 10^{12}$ & 3.79 \\
\hline HDK & $\begin{array}{l}\text { Pure } \mathrm{W}+60 \mathrm{ppm} \\
\text { of } \mathrm{K}^{[42]}\end{array}$ & $3.47^{[40]}$ & $26.52^{[40]}$ & $\begin{array}{c}111.05 \\
{[40]}\end{array}$ & $9.84 \times 10^{13}$ & 5.59 \\
\hline ALMT & $\begin{array}{c}\text { Pure W (>99.97 } \\
\%)\end{array}$ & $4.26^{[39]}$ & $9.93^{[39]}$ & $19.24^{[39]}$ & n.a. & 4.94 \\
\hline $\mathrm{W} 0.5 \mathrm{ZrC}$ & $\begin{array}{c}99.5 \% \mathrm{~W}+0.5 \% \\
\mathrm{ZrC}\end{array}$ & $2.55^{[40]}$ & $6.66^{[41]}$ & $14.15^{[40]}$ & $1.03 \times 10^{13}$ & 5.31 \\
\hline
\end{tabular}

To perform the neutron irradiation, disc shaped specimens with a thickness of $0.8 \mathrm{~mm}$ were cut using electric discharge machining (EDM) and subsequently polished to remove the EDM damage, so that the final thickness of the samples was about $0.5-0.6 \mathrm{~mm}$. A mirror-like surface was achieved before the samples were placed in the irradiation capsules. After the neutron irradiation, optical imaging confirmed that the surface kept its good quality, i.e. no traces of mechanical damage or oxidation on the surface of the sample were found.

The disk specimens were irradiated in the Belgian Reactor 2 (BR2). The specimens were placed in a steel capsule, which also act as a shield for thermal neutrons, filled with inert gas to prevent oxidation due to the high irradiation temperature. While choosing the shielding, three options were considered, namely: (i) gadolinium (Gd) foil, (ii) hafnium (Hf) foil and (iii) thick layer of the stainless steel. The advantage of $\mathrm{Gd}$ is the highest absorption rate, disadvantage relatively low melting point (around $1300^{\circ} \mathrm{C}$ ) and reactivity with water (reactor coolant), which was unacceptable in the present experiment given that the irradiation temperature on samples was planned to reach $1200{ }^{\circ} \mathrm{C}$. In addition, Gd is fast to burn up and therefore its usage for multi-cycle irradiation would lead to non-linear Re/Os generation rate, which would strongly increase after the first irradiation cycle. The advantage of $\mathrm{Hf}$ is high melting point, no chemical activity with water and low burn-up efficiency (could be used for 5 cycles, required to achieve the target dose of $1 \mathrm{dpa}$ ), but disadvantage is relatively low efficiency of absorption. To achieve the suppression of Re/Os generation rate comparable to ITER conditions, the shielding layer of Hf must be at least $1 \mathrm{~mm}$ thick, which implies strong consequences on the machining of the shielding part and high heat release due to gamma heating if the shielded rig is placed inside the fuel channel. Hence, the application of thick wall stainless steel was adopted for the shielding. The thickness of $1.5 \mathrm{~mm}$ was chosen as a compromise between the efficiency of thermal neutron absorption and volume available for the samples given the diameter of the cavity in the fuel element. The flux of thermal neutrons was cut by $20 \%$ compared to the standard thin-wall capsules typically used for the irradiation of structural steels. The efficiency of the absorption remained constant across the whole irradiation programme. The position of the specimens inside the capsule is secured by centering ceramic guiding rods in order to maintain the dedicated gap between the stack of specimens and capsule wall to achieve the required irradiation temperature. The capsules were made of thick-wall stainless steel $(1.5 \mathrm{~mm})$ and were embedded inside a fuel element to maximize the ratio of fast to thermal neutrons, which is required to suppress the transmutation of Re and Os (compared to unshielded irradiation).

The capsules with the samples were placed in different channels depending on the target fluence set to be achieved. The maximum accumulated fast neutron $(\mathrm{E}>1 \mathrm{MeV})$ fluence was $\sim 1.5 \times 10^{25} \mathrm{n} / \mathrm{m}^{2}$, a variation on the maximum fluence is $5 \%$ depending on the particular irradiation temperature. The calculation of the irradiation dose in displacement per atom (dpa) units is performed by MCNPX 2.7.0 [44] for the threshold displacement energy of $55 \mathrm{eV}$. From the MCNP calculations and reactor power measurements, the irradiation doses and temperatures were revealed to be 1.05 dpa for the fluence of $1.5 \times 10^{25} \mathrm{n} / \mathrm{m}^{2}$. The ALEPH code [45] and 
accessible nuclear cross section databases [46-48] were applied for the calculation of the transmuted Re and Os. The summed concentration of transmuted Re and Os at $1.05 \mathrm{dpa}$ is 1.92.2 at. $\%$ and $0.19-0.25$ at. $\%$, respectively, depending on the irradiation temperature. For the other doses the transmutation products scale nearly linearly. The ratio of Re to Os transmutation is close to 10. The post-irradiation MCNP calculations have revealed that the following doses were reached for Set 1: 0.12-0.15 dpa, 0.18-0.25 dpa, 0.55-0.65 dpa, 1.05-1.07 dpa; and Set 2: $0.95 \mathrm{dpa}\left(600^{\circ} \mathrm{C}\right), 1.00 \mathrm{dpa}\left(1000^{\circ} \mathrm{C}\right)$, and $1.13 \mathrm{dpa}\left(1200^{\circ} \mathrm{C}\right)$. The range of the irradiation doses for Set 1 is provided because each target dose was reached in four capsules (one capsule per irradiation temperature and irradiation dose). Typically, the capsules with the highest irradiation temperature accumulated the highest irradiation dose.

The micro-hardness was determined using the Reichert-Jung Micro-Duromat $4000 \mathrm{E}$ Vickers hardness test bench. A Vickers indenter was used with a load of $200 \mathrm{~g}$. The load was applied with a load rate of $10 \mathrm{~g} / \mathrm{s}$ and held for $10 \mathrm{~s}$. The indents were measured via an optical microscope equipped with a digital camera. The calculation of the hardness value follows the ASTM standard E384. For statistics, nine indents per sample were performed randomly across the sample's surface. In the case of single crystal samples, the micro-hardness tests were performed on (100) surface by varying the orientation of the indenter pyramid by $90^{\circ}$ to ensure that an average hardness value is properly calculated accounting for the anisotropy due to a different number of slip systems available. In the case of other W grades, the average hardness value was revealed by ten measurements taken in randomly selected areas, which typically resulted in the standard deviation being $2-4 \%$ of the mean value. The standard deviation measured in the single crystal is $8 \%$, whose origin is thoroughly explained in our previous work dedicated to the assessment of neutron irradiation effects in single crystal $W[20,49]$. The hardness tests for the ITER specification grades (which exhibit texture) are performed on the plane orthogonal to the longitudinal direction (LD) for IGP and ALMT. The results report the ideal hardness values without a correction applied for the shape of the indent. Our preliminary study applied to the single crystal (where the plasticity and heterogeneity of the deformation is the most pronounced) shows that the correction amounts to about $\sim 3 \%$ which is smaller than the $8 \%$ uncertainty associated with the mutual orientation of the sample lattice and indenter wedges. Hence, the maximum error associated with the result presented below does not exceed $8 \%$.

The TEM measurements were applied to a limited set of samples due to the fact that the irradiated samples remain essentially active after about 100 days of cooling $(>2 \mathrm{mSv} / \mathrm{h}$ ). The remaining activity precluded the application of fume hood for the conventional fabrication of the samples, and the hot cell had to be used to prepare the TEM samples. The irradiated disks were cut into pieces with a size of about $1.5 \times 1.5 \times 0.5 \mathrm{~mm}$ and then the coupons were mechanically polished using SiC paper with grit sizes of 220, 500, 1200, 2000 and 4000 to achieve 70-100 $\mu \mathrm{m}$ thickness. To remove the remnants of the glue, the samples were rinsed in ethanol and then glued on $3 \mathrm{~mm}$ copper grids with an aperture of $1 \mathrm{~mm}$. Finally, TEM specimens were polished electrochemically with a solution of $1.5 \mathrm{wt} \% \mathrm{NaOH}$ in water with applied voltage of $30 \mathrm{~V}$. The specimens were investigated with JEOL 3010 TEM operating at $300 \mathrm{kV}$. The local thickness of the specimen was determined from the CBED pattern and diffraction pattern. Several measurements in different areas were performed to make sure that the observed microstructure is indeed statistically representative.

For a better understanding of the divertor target thermal loading conditions during an actual fusion operation, we calculated temperature distributions in the tungsten monoblock of a typical divertor target under expected heat loads of two distinct operational scenarios, namely, quasi-stationary normal operation $\left(10 \mathrm{MW} / \mathrm{m}^{2}\right)$ and a typical slow transient $\left(20 \mathrm{MW} / \mathrm{m}^{2}\right)[16]$. 
The calculations were performed for the EU-DEMO divertor target monoblock geometry i.e. $23 \times 12 \times 8 \mathrm{~mm}$, which correspondingly has $8 \mathrm{~mm}$ thick tungsten layer from the copper interlayer up to the plasma-exposed surface. The calculation method and details are presented in [50]. The cooling pipe has a thickness of $1.5 \mathrm{~mm}$ and the copper interlayer $1 \mathrm{~mm}$. The boundary condition assumes a uniform heat flux density on the top surface considering the toroidal symmetry of heat fluxes. The hydraulic boundary condition for the heat removal accounts for the water cooling condition assumed for the EU-DEMO divertor (bulk temperature: $150^{\circ} \mathrm{C}$, pressure: 5 $\mathrm{MPa}$, velocity $16 \mathrm{~m} / \mathrm{s}$ ) [16].

\section{Results}

\subsection{Temperature distribution on tungsten monoblock}

Fig. 2 shows the picture of the fabricated mock-up (a) with dimensions and the calculated temperature distribution in the $\mathrm{W}$ monoblock. In the case of the steady state operation at 10 $\mathrm{MW} / \mathrm{m}^{2}$ (see Fig. 2(d)), more than a half of the armor thickness (armor is the upper region of the monoblock from the interlayer up to the plasma-loaded surface) is subjected to thermal exposure at the temperature exceeding $600^{\circ} \mathrm{C}$. The temperature at the top surface layer of about $2 \mathrm{~mm}$ reaches roughly $1200^{\circ} \mathrm{C}$.

Under the transient heat load at $20 \mathrm{MW} / \mathrm{m}^{2}$ (Fig. 2(c)), the temperature at the middle depth reaches roughly $1200^{\circ} \mathrm{C}$ whereas the maximum temperature at the top surface exceeds $2000{ }^{\circ} \mathrm{C}$. Prevailing in the large volume $(\sim 50 \%)$ of the armor region at $10-20 \mathrm{MW} / \mathrm{m}^{2}$, the temperature range $600-1200{ }^{\circ} \mathrm{C}$ seems to be a highly representative temperature window relevant for the mechanical performance of irradiated tungsten.

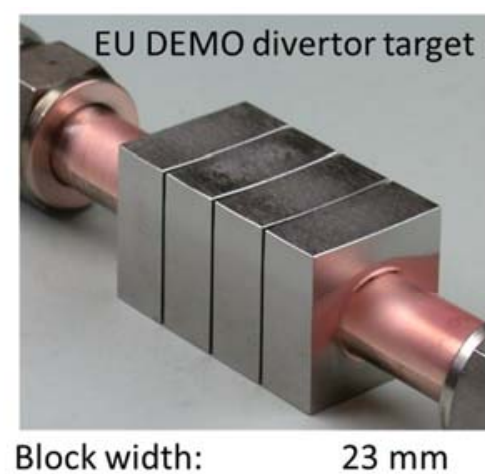

(a) Front face thickness: $8 \mathrm{~mm}$ Block axial thickness: $12 \mathrm{~mm}$

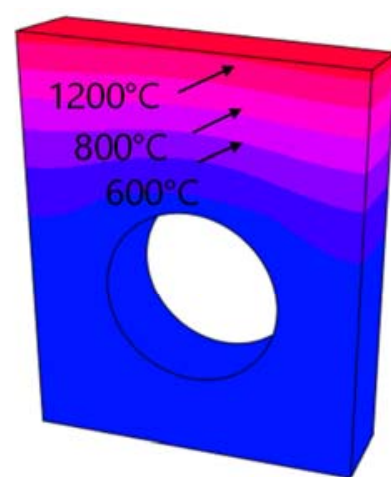

(b)

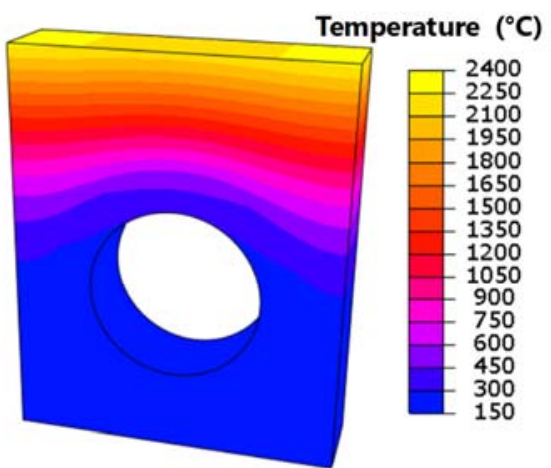

(c)

Fig.2. (a) Mock-up and typical dimensions of the $\mathrm{W}$ monoblock-type divertor target unit (current baseline for the EU-DEMO [16]). Figs.(b) and (c) show temperature distribution in the $\mathrm{W}$ monoblock simulated for the surface heat flux load of 10 and $20 \mathrm{MW} / \mathrm{m}^{2}$, respectively.

\subsection{Irradiation induced hardness in Set 1 materials}


The irradiation hardening for Set 1 samples, calculated as $H_{\text {irr }}=H_{0}^{\mathrm{irr}} / H_{0}^{\text {ref }}$ (i.e. being dimensionless) is shown in Fig. 3. Hirr is presented for the three types of materials, namely: single crystal (SC), reference ITER specification grade (IGP) and rolled plate (HDK). One should keep in mind that the uncertainty of the determination of the absolute value of the hardness for IGP and KIT is $\sim 3 \%$, and it is $8 \%$ for the SC.

It is evident that the SC exhibits the highest hardening after irradiation, irrespective of the irradiation temperature. The hardness increases by a factor of two at $1 \mathrm{dpa}$ for $\mathrm{T}_{\mathrm{irr}}=600$ and $800{ }^{\circ} \mathrm{C}$. At $\mathrm{T}_{\text {irr }}=1200{ }^{\circ} \mathrm{C}$, the hardening yields to 1.7 which is still very high given that the irradiation temperature reached $\mathrm{T}_{\mathrm{m}} / 3$ (where $\mathrm{T}_{\mathrm{m}}$ is the melting point). Given the current knowledge about the irradiation effects in structural materials for fusion applications (see review in [51] and references therein), the irradiation hardening is not expected to play any significant role (except high doses at which He accumulates) and at $\mathrm{T} / 3$ the irradiation softening and creep is of concern at least in the case of ferritic-martensitic steels and copperbased alloys [17].

As we can see from Fig.3, the maximum radiation hardening for the $\mathrm{SC}$ in the dose range of $0.6-1 \mathrm{dpa}$ is observed at $800{ }^{\circ} \mathrm{C}$, which is consistent with the reported peak swelling at $800^{\circ} \mathrm{C}$ [19]. Recently, a similar trend with irradiation temperature was registered and discussed for the same material but irradiated only up to $0.12 \mathrm{dpa}$ [20], where this finding was substantiated based on positron annihilation spectroscopy (PAS) data and complimentary object kinetic Monte Carlo (OKMC) calculations [52-54]. The maximum hardness was explained by the contribution coming from the high density of voids, while the reduction of the irradiation hardening above $800{ }^{\circ} \mathrm{C}$ was associated with decreasing a void number density as suggested by the OKMC simulations. The irradiation hardening at $600{ }^{\circ} \mathrm{C}$, on the other hand, was associated with the presence of small voids and high density of the dislocation loops.

The smallest increase of the hardness is induced in the rolled plate (HDK material). This should be attributed to the high density of the sinks (i.e. high sink strength) for the irradiation defects which result in the reduced accumulation of the voids and dislocation loops. Following this logic, the $\mathrm{H}_{\text {irr }}$ for the IGP grade should be located in the middle, and this is indeed the case.

Let us make a comparative analysis of the sink strength in the IGP and HDK materials. Let us recall that the physical meaning of the sink strength is just a probability of the interaction of a migrating defects with another object (dislocation or grain boundary in this case) i.e. crosssection, and therefore the unit of its measure is $\mathrm{m}^{-2}$. Following the current state of the radiation damage theory in metals (see e.g. a recent synopsis [55]) the formation and growth of voids occurs due to the biased absorption of self-interstitial defects. At considerable irradiation doses, voids may self-arrange into the void lattice [56] and screen each other from 1D-migrating dislocation loops. However, for both scenario the fact that diffusing irradiation defects can be absorbed by sinks (i.e. dislocations and boundaries in the case of the studied materials) is fundamental to explain the excess of vacancies and subsequently the nucleation of voids [57]. Of course, once the voids and dislocation loops grow to a certain size they also become sinks for newly injected irradiation defects, however, the initial sink strength must be responsible for the microstructure at low irradiation doses (such as studied here). The summary of sink strength models for 3D- and 1D-migrating defects is made in [58-60]. Following these works and references therein, Table 2 presents the expressions and results calculated for the sink strength of IGP and HDK materials. Naturally, 3D- and 1D - migrating defects would correspond to vacancies (and their small clusters) and self-interstitial (and their small clusters) defects, respectively. Using the mean grain size and initial dislocation density as provided in Section 2, we obtain the values for the sink strength, as provided in Table 2. As one can see, the sink strength at grain boundaries is nearly the same, whereas the sink strength due to bulk dislocations is much higher in the HDK material. This is why the absorption of in-cascade 
created 1D-migrating dislocation loops should be higher in the HDK material leading to a higher vacancy supersaturation and as a result to a higher density of voids.

Table 2. Summary of sink strength expressions. $D$ is the mean grain size. $r_{\mathrm{d}}$ is the capture radius, which can be taken as a typical size of 1d-migraing defects (here, we take it as $1 \mathrm{~nm}$ ). $p^{*}=$ $r_{\mathrm{v}} \times \sqrt{\pi \cdot p} \cdot p$ is the dislocation density.

\begin{tabular}{|l|l|l|l|}
\hline Defect type - sink type & Expression & $\begin{array}{l}\text { Sink strength in } \\
\text { IGP, } m^{-2}\end{array}$ & $\begin{array}{l}\text { Sink strength in } \\
\text { HDK, } m^{-2}\end{array}$ \\
\hline 3d-migrating at grain boundary & $14.4 / D^{2}$ & $5.78 \mathrm{E}+10$ & $2.05 \mathrm{E}+10$ \\
\hline $1 \mathrm{~d}$ migrating at grain boundary & $15 / D^{2}$ & $6.02 \mathrm{E}+10$ & $2.13 \mathrm{E}+10$ \\
\hline $3 \mathrm{~d}$ migrating at dislocations & $2 \times \pi \times p /\left(\ln \left(1 / p^{*}\right)\right)$ & $1.26 \mathrm{E}+13$ & $3.81 \mathrm{E}+14$ \\
\hline $1 \mathrm{~d}$ migrating at dislocations & $2\left(\pi \times r_{\mathrm{d}} \times p\right)^{2}$ & $3.99 \mathrm{E}+08$ & $1.91 \mathrm{E}+11$ \\
\hline
\end{tabular}

Another remarkable feature that can be seen from Fig. 3 is the change of the trend for $\mathrm{H}_{\text {irr }}$ versus dose with the increase of the irradiation temperature from 600 to $1200{ }^{\circ} \mathrm{C}$. At $\mathrm{T}_{\text {irr }}=600{ }^{\circ} \mathrm{C}$, $\mathrm{H}_{\text {irr }}$ nearly linearly increases with the irradiation dose (except for the SC, which exhibits steep rise from 0.6 to $1 \mathrm{dpa}$ ), whereas at $\mathrm{T}_{\mathrm{irr}}=1200^{\circ} \mathrm{C}$ the curves for SC and IGP acquire square root dependence on the dose. In the latter case, $\mathrm{H}_{\text {irr }}$ in SC and IGP grades clearly exhibits a cusp around $0.2 \mathrm{dpa}$, indicating that above this dose the saturation of defect density takes place, while the defect growth at higher doses provides a limited contribution to the increase of the hardness. Thus, at $\mathrm{T}_{\text {irr }}=600{ }^{\circ} \mathrm{C}$ the nucleation of the irradiation induced defects obstructing the plastic deformation lasts at least up to $1 \mathrm{dpa}$, while it ceases coming to the saturation at 1200 ${ }^{\circ} \mathrm{C}$ in the dose range of 0.2-0.6 dpa. As will be discussed later on, this is likely linked to the diffusion of dislocation loops and their absorption by microstructural defect sinks at high temperature.

For the HDK material irradiated at $800{ }^{\circ} \mathrm{C}$ and $1200{ }^{\circ} \mathrm{C}$, an incubation phase applies prior the hardness starts to increase linearly. The incubation dose lasts up to around 0.2-0.6 dpa. This might be explained by a limited capacity of the initial microstructure to suppress the void nucleation. In the case of $\mathrm{T}_{\text {irr }}=600{ }^{\circ} \mathrm{C}$, such limit does not present because besides the voids, the formation and growth of dislocation loops should contribute considerably to the increase of the hardness.

Two trends derived from the above discussed results are formulated below, being valid for all three materials constituting Set 1:

(i) the irradiation hardening exhibits linear growth at $\mathrm{T}_{\mathrm{irr}}=600$ and $800{ }^{\circ} \mathrm{C}$ in the dose range $0.2-1 \mathrm{dpa}$. While at $\mathrm{T}_{\mathrm{irr}}=1200{ }^{\circ} \mathrm{C}$, the hardening growth follows the square root dependence on the dose (except HKD material, which might be linked with an extended incubation dose).

(ii) at $1 \mathrm{dpa}$, the maximum irradiation hardness realizes at $\mathrm{T}_{\mathrm{irr}}=800{ }^{\circ} \mathrm{C}$, and there is just modest decrease of the hardness at $\mathrm{T}_{\text {irr }}=1200{ }^{\circ} \mathrm{C}$ compared to $800^{\circ} \mathrm{C}$. 


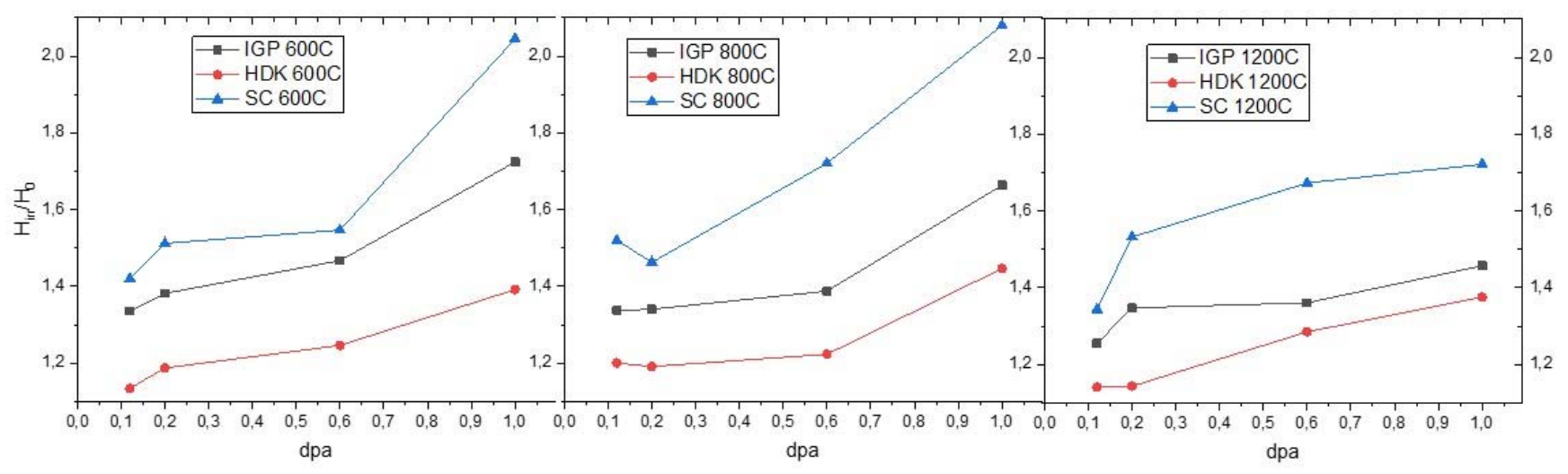

Fig.3. Evolution of the irradiation-induced hardening measured as $\mathrm{H}_{\mathrm{irr}} / \mathrm{H}_{0}$ in the Set 1 samples versus fluence (expressed in dpa) for the samples irradiated at (a) $600{ }^{\circ} \mathrm{C}$, (b) $800{ }^{\circ} \mathrm{C}$ and (d) $1200{ }^{\circ} \mathrm{C}$.

Fig.4 summarizes the hardening data obtained in this work and previously published results for the single crystal, where the irradiation was performed at the HFIR reactor in the temperature range $80-830{ }^{\circ} \mathrm{C}$ in the flux trap channel (without applying shielding) [25-27] and in the temperature range $580-780{ }^{\circ} \mathrm{C}$ using the gadolinium as thermal neutron shielding [28]. In Fig.4, we do not distinguish the data points in function of temperature and put all available data as a function of the irradiation dose. The clouds of the data points obtained at HFIR unshielded irradiation provide a trend of the parabolic increase of $\mathrm{H}_{\text {irr }}$ above certain dose, which has been already discussed by Rieth et al in [18]. As reported in [49], we found that this trend can be described as power law function of the irradiation dose with an exponent of 0.65 . As is discussed in [18], the transmutation of Re/Os begins to play an important role beyond the certain fluence, being around $10^{25} \mathrm{n} / \mathrm{m}^{2}(\mathrm{E}>0.1 \mathrm{MeV})$. By considering the results obtained at BR2 irradiation, we can see that the irradiation hardness is generally lower that the trend line, proving that the shielding applied indeed suppresses an extra hardening associated with $\mathrm{Re} / \mathrm{Os}$ transmutation. 


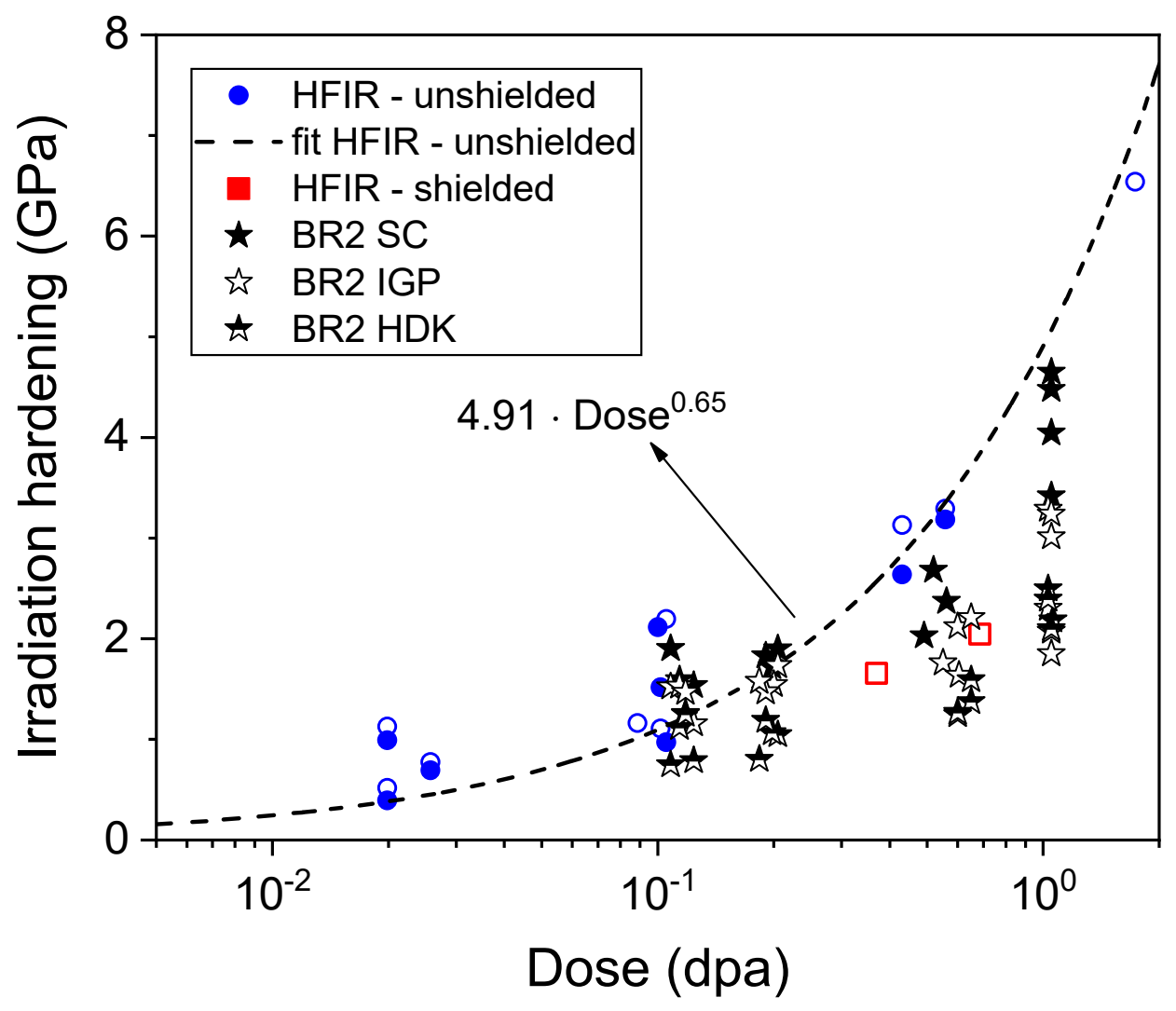

Fig.4. The difference of the hardness measured before and after the neutron irradiation of single crystal $\mathrm{W}$ performed in different reactors under various conditions versus accumulated dose. For the HFIR data, the open symbols corresponds to the (110) orientation of the surface, filled symbols represent (100) surface orientation.

\subsection{Irradiation induced hardness in Set 2 materials}

The irradiation hardening measured in Set 2 materials is shown in Fig. 5 together with the results obtained for Set 1 at $\sim 1 \mathrm{dpa}$. As in the case of Set 1 materials, we can see that the highest hardness is induced in the single crystal irrespective of the irradiation temperature. This can be explained by the fact that grain boundaries (present even in recrystallized IGP) act as sinks thereby reducing the accumulation of the irradiation defects. The lowest irradiation hardness is measured for the materials with the finest microstructure (i.e. high dislocation density and small grain/sub-grain size) such as HDK, W0.5ZrC and ALMT. It is also noticeable that for these three materials the irradiation hardness exhibits nearly no dependence on the irradiation temperature. In particular, there is no evident reduction of the hardness as $T_{\text {irr }}$ increases from $800 / 1000$ to $1200{ }^{\circ} \mathrm{C}$, unlike the case of single crystal and recrystallized IGP. This observation suggests that bulk dislocation arrays and low angle grain boundaries (present in high density in HDK, W0.5ZrC and ALMT) apparently also play an important role in the evolution of the microstructure in the temperature range of $800-1200^{\circ} \mathrm{C}$, see discussion on the sink strength in Section 3.2. The reduction of the irradiation hardness at $1200{ }^{\circ} \mathrm{C}$ in IGP and SC must be explained by the reduction of the void density as the irradiation temperature exceeds the void swelling peak [21]. Why this reduction does not take place in the fine-structure materials requires further clarification with the help of TEM and atom probe techniques (to understand location of Re and Os). 
Overall, the results presented in Fig.5 show clearly that in all studied tungsten grades, the irradiation hardening at $1200^{\circ} \mathrm{C}$ is far not negligible and the hardness increase amounts to $40 \%$ $-75 \%$ of the reference value depending on the initial microstructural state of the material.

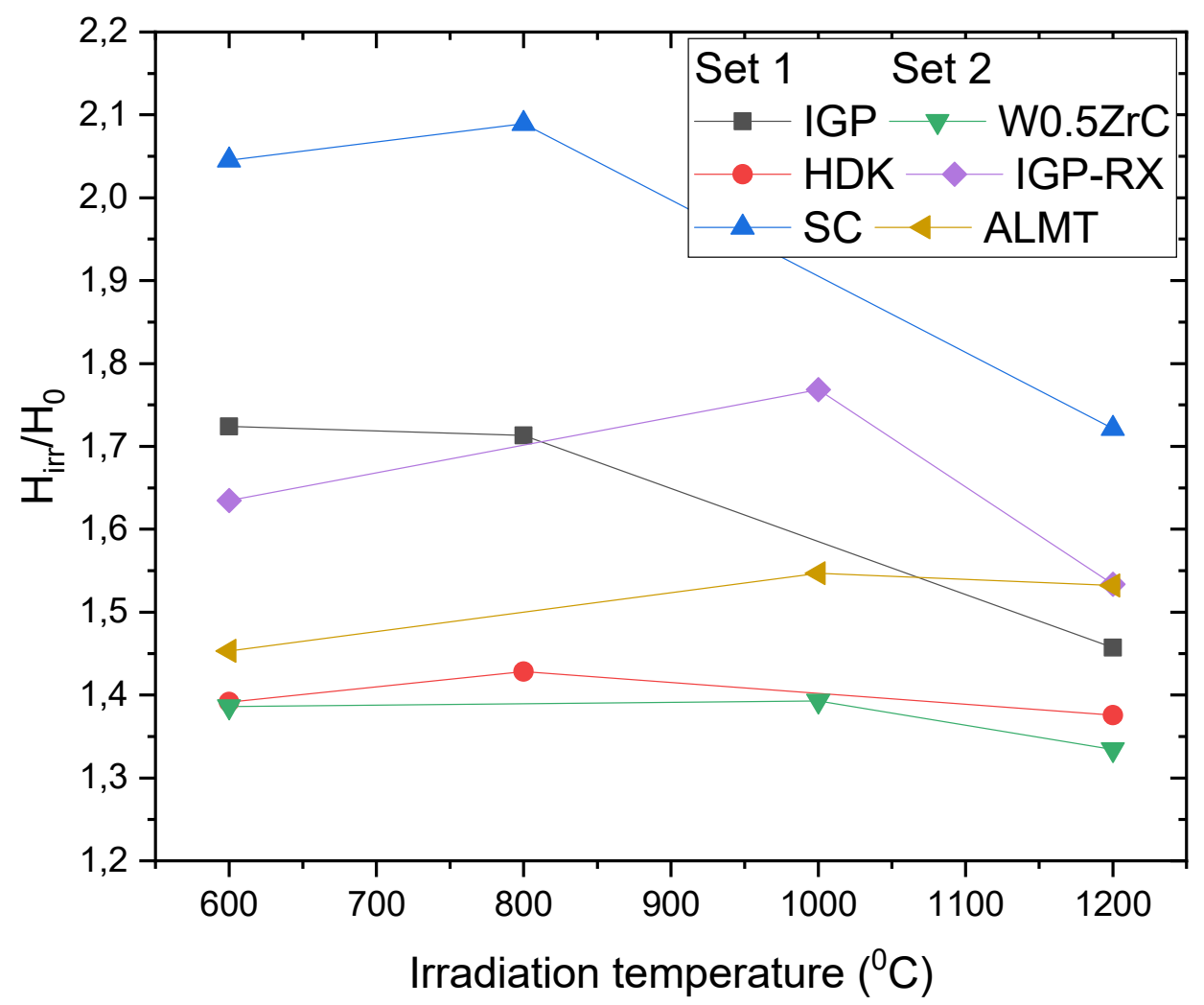

Fig.5. Irradiation hardening $\left(H_{0}^{\mathrm{irr}} / H_{0}^{\mathrm{ref}}\right)$ as a function of irradiation temperature in Set 1 and Set 2 grades. The irradiation dose for Set 1 varies from 1.03 up to $1.07 \mathrm{dpa}$. The irradiation dose for Set 2 varies from 0.95 up to $1.13 \mathrm{dpa}$.

\subsection{TEM measurements}

To reveal the origin of the irradiation induced hardness at $1200{ }^{\circ} \mathrm{C}$, we have performed screening TEM measurements. The activity on the samples irradiated to 1 dpa was about 50 $\mathrm{mSv} /$ hour, which precluded the operation with $1 \mathrm{dpa}$ irradiated samples for the preparation of TEM coupons. The highest irradiation dose for which the TEM samples were allowed to be extracted was $0.2 \mathrm{dpa}$. Out of the three materials available in Set 1, we have selected the IGP grade, being the reference material for European fusion studies [32], given its technological importance for ITER. The screening TEM measurements were performed to (i) identify typical irradiation damage defects such as voids and dislocation loops; (ii) identify possible presence of secondary phase particles like Re/Os precipitates; (iii) make an overview of the microstructure to check the sub-grain size and to estimate the dislocation line density. The identification of the loop type was out of the scope of this screening study.

The irradiated disks were cut and polished to prepare the TEM samples to investigate the microstructure after irradiation at $600{ }^{\circ} \mathrm{C}$ and $1200{ }^{\circ} \mathrm{C}$ to consider the lowest and highest irradiation temperatures, respectively. Prior to discuss the results obtained for the irradiated samples, let us briefly describe the microstructure of the non-irradiated material. The procedure 
for the sample preparation of reference and irradiated samples was the same. The typical microstructure as registered by TEM is shown in Fig.7. The sub-grains have elongated shape (see Fig.7a) and their sizes vary in the range $0.6-1.7 \mu \mathrm{m}$ and $2.3-4 \mu \mathrm{m}$, respectively, normal to and along the bar axis. The initial dislocation density is in the range $(4-8) \times 10^{12} \mathrm{~m}^{-2}$, depending on particular sub-grain, and is being $4.5 \times 10^{12} \mathrm{~m}^{-2}$ on average. Most of the grain boundaries are low-angle type grain boundaries (see Fig.7b). Few large dislocation loops were also registered in this material, see Fig.7c. In our earlier work, we discussed that these loops might have appeared because of the plastic deformation applied during the forging process [38, 61]. These loops are seen fairy rare (i.e. density is well below $10^{21} \mathrm{~m}^{-3}$ ) and their dimension usually exceeds $50 \mathrm{~nm}$ and sometimes reaches $150 \mathrm{~nm}$, so that we trust that it will be simple to distinguish these loops in the neutron irradiated samples (thus separate them from those induced by the neutron irradiation). Dislocation lines appear as isolated lines and tangles as shown in Fig.7d. Tangles usually are seen nearby grain boundary interfaces, which is apparently the result of the forging.

The TEM micrographs of the neutron irradiated samples are shown in Fig.8. The upper pane shows the patterns of the dislocation loops and the lower one - pattern of voids. The presence of non-coherent secondary phase particles was not revealed in any of the samples and areas studied. Probably, the accumulated concentration of $\operatorname{Re}(0.6 \%)$ and Os $(0.013 \%)$ is too low to induce the precipitation resolvable by TEM or any precipitation at all. Table 1 summarizes the main numerical characteristics of the microstructure registered in the reference and irradiated samples. In both irradiated samples, the appearance of the sub-grains was confirmed to be similar to the one before the irradiation in terms of size distribution and elongation. The density of the dislocation lines was found to reduce from $4.5 \times 10^{12} \mathrm{~m}^{-2}$ down to about $2 \times$ and $1.65 \times 10^{12} \mathrm{~m}^{-2}$, at the irradiation temperature of $600^{\circ} \mathrm{C}$ and $1200^{\circ} \mathrm{C}$, respectively. This is not very strong reduction given a considerable variation of the dislocation density from grain to grain. Thus, the appearance of the voids and dislocation loops is the main difference seen between the samples irradiated at 600 and $1200^{\circ} \mathrm{C}$.

At $\mathrm{T}_{\text {irr }}=600^{\circ} \mathrm{C}$, see Fig. 8 (a and c), the dislocation loops and voids are rather small in size and numerous in density. The loop and void density is measured to be $2.3 \times$ and $4.1 \times 10^{22} \mathrm{~m}^{-2}$, while the mean size is $2.8 \mathrm{~nm}$ and $1.4 \mathrm{~nm}$, respectively. The spatial distribution of the loops in some areas is non-homogeneous and decoration of the dislocation lines by the loops is evident. The voids are distributed homogeneously. No specific pattern such as void lattice is observed.

At $\mathrm{T}_{\text {irr }}=1200^{\circ} \mathrm{C}$, see Fig. 8 ( $\mathrm{b}$ and d), both types of the defects grow in size. At this, the density of the dislocation loops decreases by two orders of magnitude and goes down to $5.8 \times$ $10^{20} \mathrm{~m}^{-3}$. The mean loop size increases by a factor of two only becoming $5.1 \mathrm{~nm}$ (compared to $2.8 \mathrm{~nm}$ at $\mathrm{T}_{\text {irr }}=600^{\circ} \mathrm{C}$ ). The loop size apparently has a bimodal distribution since a number of relatively large (coffee bean - like) loops is present on the background of homogenously distributed smaller loops. Voids have also grown in size from 1.4 to $4 \mathrm{~nm}$ and their mean density is reduced by a factor of two (from 4.1 down to $1.9 \times 10^{22} \mathrm{~m}^{-3}$ ). Again, no void lattice pattern was observed, and the voids were seen to have homogeneous spatial distribution.

It is interesting to compare our results with those reported by Koyanagi et al. for single crystal irradiated at $800^{\circ} \mathrm{C}$ up to $0.15 \mathrm{dpa}$ in HFIR [62]. As in the present case, the authors have found dislocation loops and voids but not Re/Os precipitates. The loop density was $4.8 \times 10^{22} \mathrm{~m}^{-3}$ and the loop size was $2 \mathrm{~nm}$, which is comparable to the characteristics of the loops observed here at $600^{\circ} \mathrm{C}$. While the void size was $3.9 \mathrm{~nm}$ with the density of $0.2 \times 10^{22} \mathrm{~m}^{-3}$. The precipitation of $\mathrm{Re} / \mathrm{Os}$ was clearly revealed by TEM only after the irradiation dose exceeding $1 \mathrm{dpa}$. This is fully in line with the lack of the precipitates found in our samples irradiated up to $0.2 \mathrm{dpa}$.

The analysis of the contribution provided by the dislocation loops and voids to the increase of the hardness has been carried out recently by $\mathrm{Hu}$ et al. [63]. Different hardening models were exploited and applied to obtain the best fit using the data at the low dpa irradiation, 
where the Re/Os precipitation should not play an important role just as in the present case. The overall conclusion was that the dislocation loops are rather weak obstacles (with barrier strength of 0.15), while the strength of the voids depends on the size and it increases from 0.25 up to 0.4 as the void size increases from 1-2 $\mathrm{nm}$ up to $4 \mathrm{~nm}$ (and higher). It is indeed well known known that voids are becoming strong obstacles in BCC metals as their size exceeds $2 \mathrm{~nm}[64,65]$. We have applied the same analysis as $\mathrm{Hu}$ et al. [63] and calculated the expected increase of the hardness, $\Delta \mathrm{H}_{\text {calc }}=3.2 \mathrm{M} \cdot \alpha \cdot \mu \mathrm{b} \cdot(\mathrm{Nd})^{1 / 2}$. Here, $\mathrm{M}=3.06, \mu=161 \mathrm{GPa}$, and $\mathrm{N}-$ density of defects, $d$ - mean size of the defects. The contributions were separately assessed for the voids and loops and after that linear and square superposition law was used to deduce the resulting hardness increase. The results are summarized in Table 4 . As one can see, by taking the strength coefficients $\alpha$ as suggested by $\mathrm{Hu}$ et al. [63] we obtain very good agreement for $\Delta \mathrm{H}$ at $\mathrm{T}_{\mathrm{irr}}=1200$ ${ }^{\circ} \mathrm{C}$, namely 1.57 (experiment) vs. $1.58 \mathrm{GPa}$. This good agreement is obtained for the linear superposition, which is expected to be applied for this due to the very low density of the loops. In the case of $\mathrm{T}_{\text {irr }}=600{ }^{\circ} \mathrm{C}$, the two superposition laws yield to 1.31 (linear) and 0.95 (squared) vs. $1.72 \mathrm{GPa}$ obtained experimentally. It is interesting to note that for the void strength coefficient 0.4 , the $\Delta \mathrm{H}_{\text {calc }}$ (linear) $=1.79 \mathrm{GPa}$ - which is much closer to the experimental value.

Based on the TEM results and simple calculations applying the dispersed barrier model, we can conclude that the main contribution to the increase of the hardness in our samples comes from the voids as their density remains rather high at both irradiation temperatures. Although with an increase of the irradiation temperature up $1200^{\circ} \mathrm{C}$, the density of the voids was reduced, it has been compensated by the increase of the void size.

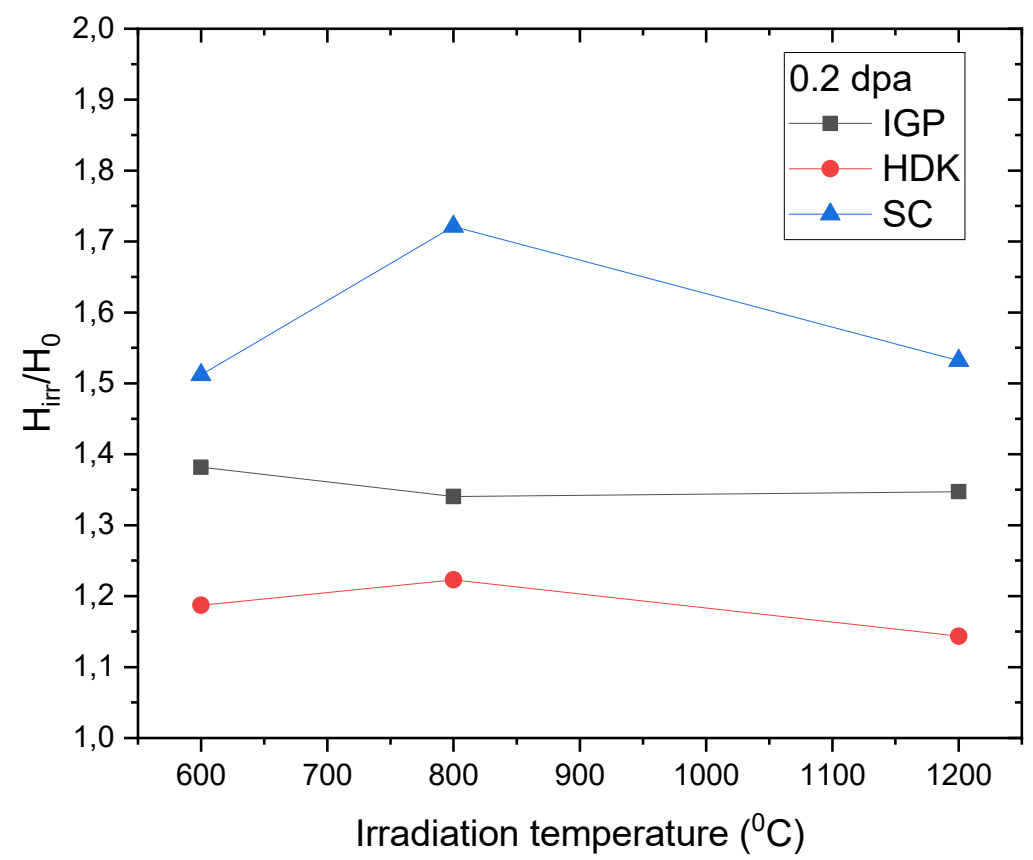

Fig. 6. Irradiation hardening $\left(H_{0}^{\mathrm{irr}} / H_{0}^{\mathrm{ref}}\right)$ induced in Set 1 materials at $0.2 \mathrm{dpa}$. 

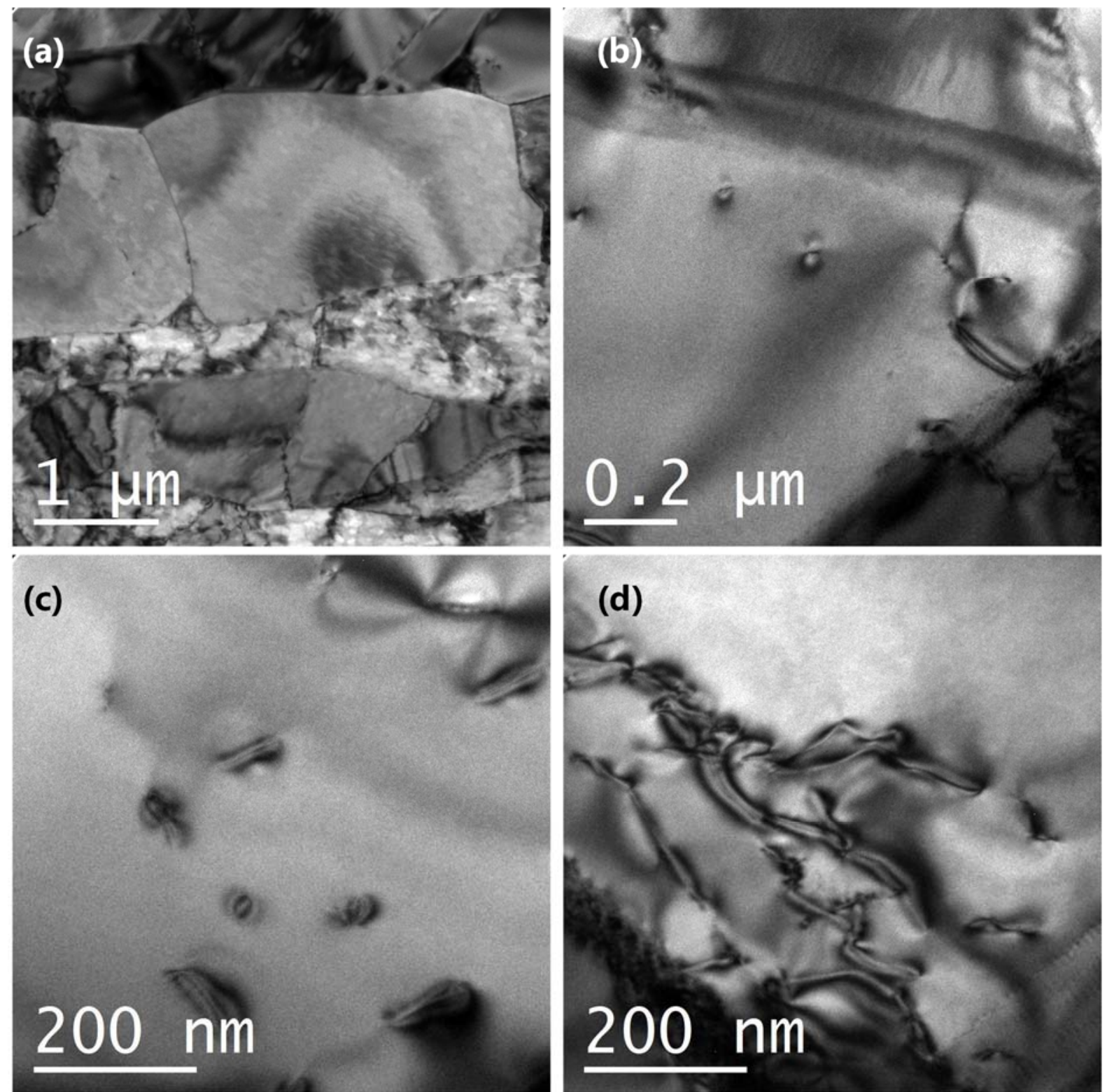

Fig.7. Bright field TEM images of typical microstructure registered in the non-irradiated IGP tungsten. (a) low magnificent image showing several sub-grains which are elongated in the left-right direction; (b) pattern of low angle grain boundary; (c) appearance of dislocation loops; (d) appearance of dislocation lines. 

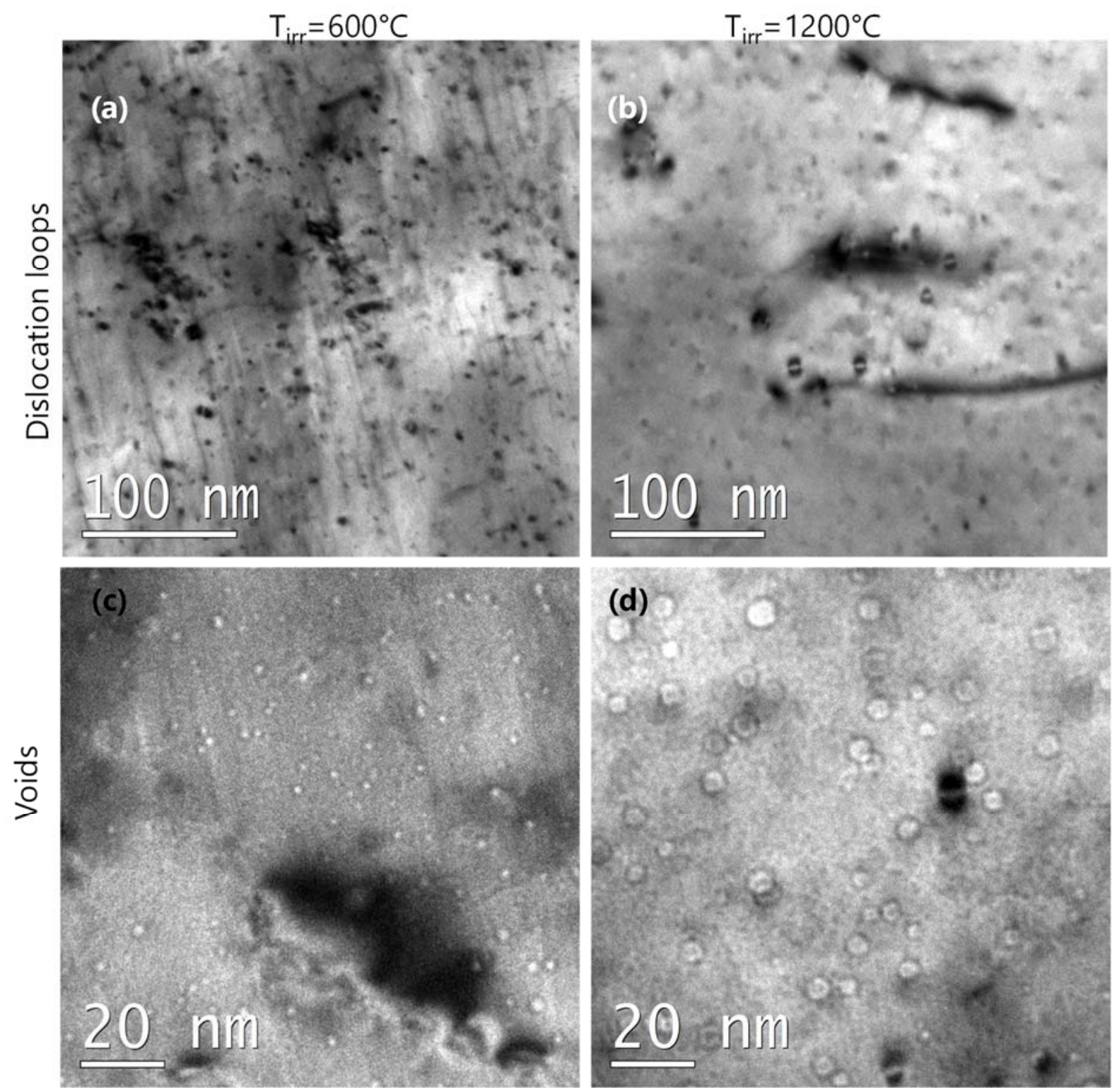

Fig.8. Bright field TEM images of typical pattern of (a,b) dislocation loops and voids (c,d) observed in IGP tungsten after neutron irradiation up to $0.2 \mathrm{dpa}$ at $(\mathrm{a}, \mathrm{c}) 600{ }^{\circ} \mathrm{C}$ and (b,d) 1200 ${ }^{\circ} \mathrm{C}$.

Table 3. Microstructural information on the IGP material before and after irradiation at 0.2 dpa.

\begin{tabular}{|l|l|l|l|l|l|l|}
\hline Condition & $\begin{array}{l}\text { Dislocation } \\
\text { density, } \\
{\left[\mathrm{m}^{-2}\right]}\end{array}$ & $\begin{array}{l}\text { Sub-grain } \\
\text { size, }[\mu \mathrm{m}]\end{array}$ & $\begin{array}{l}\text { Loop } \\
\text { density, } \\
{\left[\mathrm{m}^{-3}\right]}\end{array}$ & $\begin{array}{l}\text { Loop } \\
\text { mean size, } \\
{[\mathrm{nm}]}\end{array}$ & $\begin{array}{l}\text { Void } \\
\text { density, } \\
{\left[\mathrm{m}^{-3}\right]}\end{array}$ & $\begin{array}{l}\text { Void } \\
\text { mean } \\
\text { size, }[\mathrm{nm}]\end{array}$ \\
\hline Reference & $4.50 \times 10^{12}$ & $\begin{array}{l}0.6-1.7 \text { in } \\
\text { T direction } \\
2.3-4 \text { in } \\
\text { L direction }\end{array}$ & & $*$ & & \\
\hline Tirr $=600^{\circ} \mathrm{C}$ & $2.00 \times 10^{12}$ & Unchanged & $2.3 \times 10^{22}$ & 2.8 & $4.1 \times 10^{22}$ & 1.4 \\
\hline Tirr $=1200^{\circ} \mathrm{C}$ & $1.65 \times 10^{12}$ & Unchanged & $5.8 \times 10^{20}$ & 5.1 & $1.9 \times 10^{22}$ & 4 \\
\hline
\end{tabular}

* see remark in the text regarding the presence of the loops in the non-irradiated samples. 
Table 4. Hardness measured for IGP at $0.2 \mathrm{dpa} . \Delta \mathrm{H}_{\text {calc }}=3.2 \mathrm{M} \cdot \alpha \cdot \mu \mathrm{b} \cdot(\mathrm{Nd})^{1 / 2}$. The strength of the loops and voids were taken following $\mathrm{Hu}$ et al. [63]. $\mu=161 \mathrm{GPa} . \mathrm{M}=3.06$ [66].

\begin{tabular}{|l|l|l|l|l|l|l|l|}
\hline Tirr & $\begin{array}{l}\mathrm{H}_{0}{ }^{\text {ref }} \\
{[\mathrm{GPa}]}\end{array}$ & $\begin{array}{l}\mathrm{H}_{0}{ }^{\text {irr }} \\
{[\mathrm{GPa}]}\end{array}$ & $\begin{array}{l}\Delta \mathrm{H}_{\exp } \\
{[\mathrm{GPa}]}\end{array}$ & $\alpha$ loops & $\alpha$ voids & $\begin{array}{l}\Delta \mathrm{H}_{\text {calc }} \\
\text { Squared } \\
{[\mathrm{GPa}]}\end{array}$ & $\begin{array}{l}\Delta \mathrm{H}_{\text {calc }} \\
\text { Linear } \\
{[\mathrm{GPa}]}\end{array}$ \\
\hline $600 \mathrm{C}$ & 4.54 & 6.26 & $\mathbf{1 . 7 2}$ & 0.15 & 0.25 & $\mathbf{1 . 3 1}$ & $\mathbf{0 . 9 5}$ \\
\hline $1200 \mathrm{C}$ & 4.54 & 6.11 & $\mathbf{1 . 5 7}$ & 0.15 & 0.4 & $\mathbf{1 . 5 8}$ & $\mathbf{1 . 4 8}$ \\
\hline $600 \mathrm{C}$ & 4.54 & 6.26 & $\mathbf{1 . 7 2}$ & 0.15 & 0.4 & $\mathbf{1 . 7 9}$ & $\mathbf{1 . 3 8}$ \\
\hline
\end{tabular}

\subsection{Implication of irradiation hardening on structural integrity}

Concerning the mechanical robustness and structural integrity of the W monoblock-type targets during fusion operation, embrittlement and hardening are the most significant effects of neutron irradiation. The respective impact of these effects on structural integrity may differ one from another depending on material, fluence, temperature and stress state. While embrittlement is generally deemed to be detrimental, hardening as such can be beneficial for structural integrity since the yield stress increases (likely the ultimate tensile strength as well) reducing the risk of low cycle fatigue or fast fracture. This aspect is particularly relevant for those tungsten armor regions where high tensile stress prevails.

he stress state plotted in Fig.9 was calculated for fully brittle (i.e. linear elastic) tungsten. The maximum stress reaches $1000 \mathrm{MPa}$ in the stress concentration regions where temperature is around $300^{\circ} \mathrm{C}$ (below DBTT). Following the fracture mechanics studies presented in [67, 68 ], the considerable irradiation hardening $(\sim 40 \%)$ induced in the commercial tungsten grades below $600{ }^{\circ} \mathrm{C}$ already at a low dpa level indicates that the risk of a brittle failure will be essentially reduced even in a fully embrittled state. For example in Ref. [36], it is established that the measured tensile fracture stress of a commercial grade tungsten (very similar to the IGP and A.L.M.T. studied here) irradiated to $1 \mathrm{dpa}$ at $600^{\circ} \mathrm{C}$ was about $1200 \mathrm{MPa}$ at $400-500^{\circ} \mathrm{C}$. This indicates that the maximum tensile stress under $20 \mathrm{MW} / \mathrm{m}^{2}$ remains below the ultimate stress of irradiated tungsten.

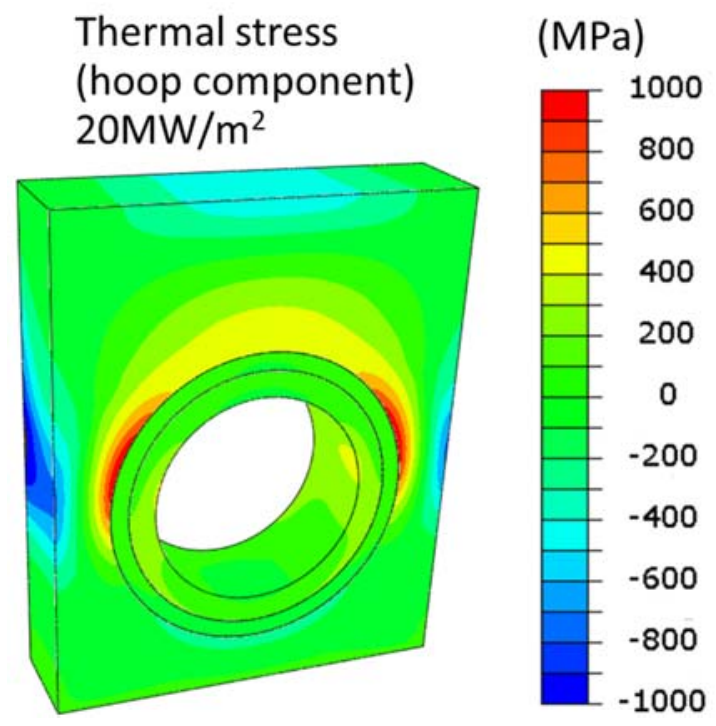

Fig.9. Thermal stress field building up in a W monoblock unit of the ITER-like divertor target (dimensions adapted for the EU-DEMO) under the surface heat flux load at $20 \mathrm{MW} / \mathrm{m}^{2}$ (hoop stress component in the cylindrical coordinate system) [67]. 


\section{Conclusions}

In this work, we have performed hardness measurements in several tungsten grades irradiated in the temperature range $600-1200{ }^{\circ} \mathrm{C}$ up to $1 \mathrm{dpa}$. Two sets of different tungsten materials were irradiated, Set 1 - to explore the effect of initial microstructure on the evolution of the hardness as a function of irradiation dose and temperature; Set 2 - to explore the accumulation of irradiation damage up $1 \mathrm{dpa}$ as a function of irradiation temperature in technologically relevant grades. To substantiate the selection of the irradiation temperatures, Thermal calculations revealing the temperature distribution in the ITER monoblock (for the nuclear phase operation) at 10 and $20 \mathrm{MW} / \mathrm{m}^{2}$ heat load was performed to substantiate the selection of the irradiation temperatures.

Based on the presented results and their discussion, the following conclusions can be stated:

(i) In general, tungsten grades with the highest initial defect density (i.e. grain boundary and dislocation density) experience the lowest increase of the hardness. The single crystal exhibits the highest hardening irrespective of the irradiation temperature and irradiation dose $(0.1-0.2$ - 0.6 - $1 \mathrm{dpa}$ ). The hardness increases by a factor of two at $1 \mathrm{dpa}$ for $\mathrm{T}_{\mathrm{irr}}=600$ and $800{ }^{\circ} \mathrm{C}$. At $\mathrm{T}_{\text {irr }}=1200{ }^{\circ} \mathrm{C}$, the hardness raises by $70 \%$ which is still very high increase given that the irradiation temperature reached one third of the melting point. However, the obtained high temperature irradiation hardening is consistent with earlier studies, in which only the microstructure was explored but not mechanical properties.

(ii) Both single crystal and ITER specification tungsten exhibit the maximum irradiation hardening at $\mathrm{T}_{\mathrm{irr}}=800{ }^{\circ} \mathrm{C}$, which is consistent with the reported peak swelling at $800{ }^{\circ} \mathrm{C}$ [19]. The computational analysis using object kinetic Monte Carlo calculations [52-54] also supports this finding.

(iii) Both single crystal and ITER specification tungsten exhibit linear growth of the hardening at $\mathrm{T}_{\text {irr }}=600-800{ }^{\circ} \mathrm{C}$ as the dose increase from 0.2 to $1 \mathrm{dpa}$. While at $\mathrm{T}_{\text {irr }}=1200{ }^{\circ} \mathrm{C}$, the hardening growth follows the square root dependence on the dose. Apparently, the saturation of the irradiation defect density takes place above $1 \mathrm{dpa}$ at $\mathrm{T}_{\text {irr }}=600-800{ }^{\circ} \mathrm{C}$, while it occurs around 0.2-0.6 dpa at at $\mathrm{T}_{\mathrm{irr}}=1200{ }^{\circ} \mathrm{C}$.

(iv) Screening TEM study was applied for the ITER specification tungsten (IGP) irradiated at $0.2 \mathrm{dpa}$ at 600 and $1200{ }^{\circ} \mathrm{C}$. TEM inspection revealed the presence of voids and dislocation loops at both irradiation temperatures. The application of the dispersed barrier hardening model with strength coefficients independently derived in [63] provided good agreement with the experimentally measured hardness values.

\section{Acknowledgements}

This work has been carried out within the framework of the EUROfusion Consortium and has received funding from the Euratom research and training programme 2014-2018 and 2019-2020 under grant agreement No. 633053. The views and opinions expressed herein do not necessarily reflect those of the European Commission. The technical staff of BR2 and Hotlab at SCK CEN is acknowledged for technical support. The support of FOD is greatly appreciated. One of the 
authors (JHY) is grateful to Dr. Kuo Zhang (IPP) for his assistance in producing figures from the FEM data files.

\section{References}

[1] S.J. Zinkle, Fusion materials science: Overview of challenges and recent progress, Phys Plasmas 12(5) (2005) 058101.

[2] S. Matsuda, K. Tobita, Evolution of the ITER program and prospect for the next-step fusion DEMO reactors: status of the fusion energy R\&D as ultimate source of energy, Journal of NUCLEAR SCIENCE and TECHNOLOGY 50(4) (2013) 321-345.

[3] M. Rieth, D. Armstrong, B. Dafferner, S. Heger, A. Hoffmann, M.-D. Hofmann, U. Jäntsch, Tungsten as a Structural Divertor Material, Advances in Science and Technology 73 (2010) 11-21.

[4] M. Rieth, D. Armstrong, B. Dafferner, S. Heger, A. Hoffmann, M. Hoffmann, U. Jäntsch, C. Kübel, E. Materna-Morris, J. Reiser, M. Rohde, T. Schrerer, V. Widak, H. Zimmermann, Tungsten as a Structural Divertor Material, Advances in Science and Technology 73 (2010) 11-21.

[5] S.J. Zinkle, Advanced materials for fusion technology, Fusion Engineering and Design 74(1-4) (2005) 31-40.

[6] A. Giannattasio, Z. Yao, E. Tarleton, S.G. Roberts, Brittle-ductile transitions in polycrystalline tungsten, Philos. Mag. 90 (2010) 3947-3959.

[7] R.H. Titran, J.R. Stephens, D.W. Petrasek, Refractory-Metal Alloys and Composites for Space Nuclear-Power Systems, Jom-J Min Met Mat S 40(7) (1988) A63-A63.

[8] B. Gludovatz, S. Wurster, A. Hoffmann, R. Pippan, Fracture toughness of polycrystalline tungsten alloys, Int J Refract Met H 28(6) (2010) 674-678.

[9] C. Bonnekoh, A. Hoffmann, J. Reiser, The brittle-to-ductile transition in cold rolled tungsten: On the decrease of the brittle-to-ductile transition by $600 \mathrm{~K}$ to- 65 degrees $\mathrm{C}$, Int J Refract Met H 71 (2018) 181-189.

[10] V. Nikolic, S. Wurster, D. Firneis, R. Pippan, Fracture toughness evaluation of UFG tungsten foil, Int J Refract Met H 76 (2018) 214-225.

[11] J. Reiser, S. Wurster, J. Hoffmann, S. Bonk, C. Bonnekoh, D. Kiener, R. Pippan, A. Hoffmann, M. Rieth, Ductilisation of tungsten (W) through cold-rolling: R-curve behaviour, Int J Refract Met H 58 (2016) 22-33.

[12] G. Pintsuk, Tungsten as plasma facing material, Comprehensive Nuclear Materials 4 (2012) 551581.

[13] T. Hirai, S. Panayotis, V. Barabash, Et.al., Use of tungsten material for the ITER divertor, Nuclear Materials and Energy 000 (2016) 1-7.

[14] M.Y. Li, E. Werner, J.H. You, Influence of heat flux loading patterns on the surface cracking features of tungsten armor under ELM-like thermal shocks, Journal of Nuclear Materials 457 (2015) 256-265.

[15] M.Y. Li, J.H. You, Interpretation of the deep cracking phenomenon of tungsten monoblock targets observed in high-heat-flux fatigue tests at $20 \mathrm{MW} / \mathrm{m}(2)$, Fusion Engineering and Design 101 (2015) 1-8.

[16] J.H. You, E. Visca, T. Barrett, B. Boswirth, F. Crescenzi, F. Domptail, M. Fursdon, F. Gallay, B.E. Ghidersae, H. Greunera, M. Li, A.V. Muller, J. Reiser, M. Richou, S. Roccella, C. Vorpahl, European divertor target concepts for DEMO: Design rationales and high heat flux performance, Nuclear Materials and Energy 16 (2018) 1-11.

[17] D. Stork, P. Agostini, J.L. Boutard, D. Buckthorpe, E. Diegele, S.L. Dudarev, C. English, G. Federici, M.R. Gilbert, S. Gonzalez, A. Ibarra, C. Linsmeier, A. Li Puma, G. Marbach, P.F. Morris, L.W. Packer, B. Raj, M. Rieth, M.Q. Tran, D.J. Ward, S.J. Zinkle, Developing structural, high-heat flux and plasma facing materials for a near-term DEMO fusion power plant: The EU assessment, Journal of Nuclear Materials 455(1-3) (2014) 277-291.

[18] M. Rieth, R. Doerner, A. Hasegawa, Y. Ueda, M. Wirtz, Behavior of tungsten under irradiation and plasma interaction, Journal of Nuclear Materials 519 (2019) 334-368. 
[19] J. Matolich, H. Nahm, J. Moteff, Swelling in neutron irradiated tungsten and tungsten-25 rhenium, Scripta Metall Mater 8 (1974) 837-842.

[20] G. Bonny, M.J. Konstantinovic, A. Bakaeva, C. Yin, N. Castin, K. Mergia, V. Chatzikos, S. Dellis, T. Khvan, A. Bakaev, A. Dubinko, D. Terentyev, Trends in vacancy distribution and hardness of high temperature neutron irradiated single crystal tungsten, Acta Mater. 198 (2020) 1-9.

[21] F. Ferroni, X. Yi, K. Arakawa, S.P. Fitzgerald, P.D. Edmonds, S.G. Roberts, High temperature annealing of ion irradiated tungsten, Acta Materialia 90 (2015) 380-393.

[22] T. Miyazawa, L.M. Garrison, J.W. Geringer, M. Fukuda, Y. Katoh, T. Hinoki, A. Hasegawa, Neutron irradiation effects on the mechanical properties of powder metallurgical processed tungsten alloys, Journal of Nuclear Materials 529 (2020).

[23] W.Z. Yao, P. Wang, A. Manhard, C.E. Krill, J.H. You, Effect of hydrogen on the slip resistance of tungsten single crystals, Mat Sci Eng a-Struct 559 (2013) 467-473.

[24] W.Z. Yao, C.E. Krill, B. Albinski, H.C. Schneider, J.H. You, Plastic material parameters and plastic anisotropy of tungsten single crystal: a spherical micro-indentation study, J Mater Sci 49(10) (2014) 3705-3715.

[25] L.M. Garrison, Y. Katoh, N.A.P.K. Kumar, Mechanical properties of single-crystal tungsten irradiated in a mixed spectrum fission reactor, Journal of Nuclear Materials 518 (2019) 208-225.

[26] M. Fukuda, N.A.P. Kiran Kumar, T. Koyanagi, L.M. Garrison, L.L. Snead, Y. Katoh, A. Hasegawa, Neutron energy spectrum influence on irradiation hardening and microstructural development of tungsten, Journal of Nuclear Materials 479 (2016) 249-254.

[27] X. Hu, T. Koyanagi, M. Fukuda, N.A.P.K. Kumar, L.L. Snead, B.D. Wirth, Y. Katoh, Irradiation hardening of pure tungsten exposed to neutron irradiation, Journal of Nuclear Materials 480 (2016) 235-243.

[28] L.M. Garrison, Y. Katoh, J.W. Geringer, M. Akiyoshi, X. Chen, M. Fukuda, A. Hasegawa, T. Hinoki, X. Hu, T. Koyanagi, E. Lang, M. McAlister, J. McDuffee, T. Miyazawa, C. Parish, E. Proehl, N. Reid, J. Robertson, H. Wang, PHENIX U.S.-Japan Collaboration Investigation of Thermal and Mechanical Properties of Thermal Neutron-Shielded Irradiated Tungsten, Fusion Science and Technology 75(6) (2019) 499-509.

[29] C. Yin, D. Terentyev, T. Pardoen, A. Bakaeva, R. Petrov, S. Antusch, M. Rieth, M. Vilemova, J. Matejicek, T. Zhang, Tensile properties of baseline and advanced tungsten grades for fusion applications, Int J Refract Met H 75 (2018) 153-162.

[30] V. Barabash, G. Federici, M. Rodig, L.L. Snead, C.H. Wu, Neutron irradiation effects on plasma facing materials, Journal of Nuclear Materials 283 (2000) 138-146.

[31] S. Krimpalis, K. Mergia, S. Messoloras, A. Dubinko, D. Terentyev, K. Triantou, J. Reiser, G. Pintsuk, Comparative study of the mechanical properties of different tungsten materials for fusion applications, Physica Scripta T170 (2017).

[32] M. Wirtz, J. Linke, T. Loewenhoff, G. Pintsuk, I. Uytdenhouwen, Thermal shock tests to qualify different tungsten grades as plasma facing material, Physica Scripta T167 (2016) 014015.

[33] S. Nogami, A. Hasegawa, M. Fukuda, S. Watanabe, J. Reiser, M. Rieth, Tungsten modified by potassium doping and rhenium addition for fusion reactor applications, Fusion Eng. Des. 152 (2020) 111445.

[34] J. Reiser, J. Hoffmann, U. Jantsch, M. Klimenkov, S. Bonk, C. Bonnekoh, A. Hoffmann, T. Mrotzek, M. Rieth, Ductilisation of tungsten (W): On the increase of strength AND room-temperature tensile ductility through cold-rolling, Int J Refract Met H 64 (2017) 261-278.

[35] Z.M. Xie, R. Liu, S. Miao, X.D. Yang, T. Zhang, X.P. Wang, Q.F. Fang, C.S. Liu, G.N. Luo, Y.Y. Lian, X. Liu, Extraordinary high ductility/strength of the interface designed bulk W-ZrC alloy plate at relatively low temperature, Sci Rep-Uk 5 (2015).

[36] C. Yin, D. Terentyev, T. Zhang, R.H. Petrov, T. Pardoen, Impact of neutron irradiation on the strength and ductility of pure and $\mathrm{ZrC}$ reinforced tungsten grades, Journal of Nuclear Materials 537 (2020).

[37] A. Dubinko, C. Yin, D. Terentyev, A. Zinovev, M. Rieth, S. Antusch, M. Vilemova, J. Matejicek, T. Zhang, Plastic deformation in advanced tungsten-based alloys for fusion applications studied by 
mechanical testing and TEM, Int J Refract Met $\mathrm{H}$ in press, https://doi.org/10.1016/j.ijrmhm.2020.105409 (2020) 105409.

[38] A. Dubinko, D. Terentyev, A. Bakaeva, K. Verbeken, M. Wirtz, M. Hernandez-Mayoral, Evolution of plastic deformation in heavily deformed and recrystallized tungsten of ITER specification studied by TEM, Int. Journal of Refractory Metals and Hard Materials 66 (2017) 105-115.

[39] C. Yin, D. Terentyev, A. Dubinko, T. Zhang, M. Wirtz, S. Antusch, R. Petrov, T. Pardoen, Impact of neutron irradiation on hardening of baseline and advanced tungsten grades and its link to initial microstructure, J. Nucl. Mater. (2020) submitted.

[40] C. Yin, D. Terentyev, T. Zhang, S. Nogami, S. Antusch, C.-C. Chang, R. Petrov, T. Pardoen, Ductile to Brittle Transition Temperature of advanced tungsten alloys for nuclear fusion applications deduced by miniaturized three-point bending tests, Int. J. Refract. Met. Hard Mater. (2020) Submitted.

[41] C. Yin, D. Terentyev, T. Pardoen, A. Bakaeva, R. Petrov, S. Antusch, M. Rieth, M. Vilemova, J. Matejicek, T. Zhang, Tensile properties of baseline and advanced tungsten grades for fusion applications, Int. J. Refract. Met. Hard Mater. 75 (2018) 153-162.

[42] P. Lied, C. Bonnekoh, W. Pantleon, M. Stricker, A. Hoffmann, J. Reiser, Comparison of K-doped and pure cold-rolled tungsten sheets: As-rolled condition and recrystallization behaviour after isochronal annealing at different temperatures, Int. J. Refract. Met. Hard Mater. 85 (2019) 105047. [43] Z.M. Xie, R. Liu, S. Miao, X.D. Yang, T. Zhang, X.P. Wang, Q.F. Fang, C.S. Liu, G.N. Luo, Y.Y. Lian, X. Liu, Extraordinary high ductility/strength of the interface designed bulk W-ZrC alloy plate at relatively low temperature, Scientific Reports 5 (2015) 1-11.

[44] D. Pelowitz, J. Durkee, J. Elson, M. Fensin, M. James, R. Johns, G. McKinney, S. Mashnik, L. Waters, T. Wilcox, MCNPX 2.7. 0 Extensions, Los Alamos National Laboratory, 2011.

[45] A. Stankovskiy, G. Van den Eynde, L. Fiorito, ALEPH V.2.7, A Monte Carlo Burn-Up Code, SCK CEN, 2018.

[46] JEFF Scientific Working group, The joint evaluated fission and fusion nuclear data library, JEFF3.3, Nuclear Energry Agency, 2017.

[47] D.A. Brown, M. Chadwick, R. Capote, A. Kahler, A. Trkov, M. Herman, A. Sonzogni, Y. Danon, A. Carlson, M. Dunn, ENDF/B-VIII. 0: the 8th major release of the nuclear reaction data library with CIELO-project cross sections, new standards and thermal scattering data, Nuclear Data Sheets 148 (2018) 1-142.

[48] A.Y. Konobeyev, U. Fischer, Y.A. Korovin, S. Simakov, Evaluation of effective threshold displacement energies and other data required for the calculation of advanced atomic displacement cross-sections, Nuclear Energy and Technology 3(3) (2017) 169-175.

[49] C. Yin, G. Bonny, D. Terentyev, Anisotropy in the hardness of single crystal tungsten before and after neutron irradiation, Journal of Nuclear Materials (2020) submitted.

[50] M. Li, J.H. You, Structural impact of creep in tungsten monoblock divertor target at $20 \mathrm{MW} / \mathrm{m}(2)$, Nuclear Materials and Energy 14 (2018) 1-7.

[51] S.J. Zinkle, J.T. Busby, Structural materials for fission \& fusion energy, Materials today 12 (2009).

[52] N. Castin, A. Bakaev, G. Bonny, A.E. Sand, L. Malerba, D. Terentyev, On the onset of void swelling in pure tungsten under neutron irradiation: An object kinetic Monte Carlo approach, Journal of Nuclear Materials 493 (2017) 280-293.

[53] N. Castin, G. Bonny, A. Bakaev, C.J. Ortiz, A.E. Sand, D. Terentyev, Object kinetic Monte Carlo model for neutron and ion irradiation in tungsten: Impact of transmutation and carbon impurities, Journal of Nuclear Materials 500 (2018) 15-25.

[54] N. Castin, A. Dubinko, G. Bonny, A. Bakaev, J. Likonen, A. De Backer, A.E. Sand, K. Heinola, D. Terentyev, The influence of carbon impurities on the formation of loops in tungsten irradiated with self-ions, Journal of Nuclear Materials 527 (2019) 151808.

[55] A.V. Barashev, S.I. Golubov, Radiation Damage Theory: Past, Present and Future, Materials for Future Fusion and Fission Technologies 1125 (2009) 127-132

141. 
[56] H. Heinisch, B. Singh, The effect of one-dimensional migration of self-interstitial clusters on the formation of void lattices, Journal of Nuclear Materials 307-311 (2002) 876-880.

[57] A. Brailsford, J. Matthews, R. Bullough, The effect of recombination on sink strengths in the rate theory of void-swelling, Journal of Nuclear Materials 79 (1979) 1-13.

[58] L. Malerba, C. Becquart, C. Domain, Object kinetic Monte Carlo study of sink strengths, Journal of Nuclear Materials 360 (2007) 159-169.

[59] V. Jansson, L. Malerba, Simulation of the nanostructure evolution under irradiation in Fe-C alloys, Journal of Nuclear Materials 443(1-3) (2013) 274-285.

[60] A. Barashev, S. Golubov, H. Trinkaus, Reaction kinetics of glissile interstitial clusters in a crystal containing voids and dislocations, Philosophical Magazine A 81(10) (2001) 2515-2532.

[61] A. Dubinko, D. Terentyev, A. Bakaeva, T. Pardoen, M. Zibrov, T.W. Morgan, Effect of high flux plasma exposure on the micro-structural and -mechanical properties of ITER specification tungsten, Nucl Instrum Meth B 393 (2017) 155-159.

[62] T. Koyanagi, N.A.P.K. Kumar, T. Hwang, L.M. Garrison, X.X. Hu, L.L. Snead, Y. Katoh, Microstructural evolution of pure tungsten neutron irradiated with a mixed energy spectrum, Journal of Nuclear Materials 490 (2017) 66-74.

[63] X.X. Hu, T. Koyanagi, M. Fukuda, N.A.P.K. Kumar, L.L. Snead, B.D. Wirth, Y. Katoh, Irradiation hardening of pure tungsten exposed to neutron irradiation, Journal of Nuclear Materials 480 (2016) 235-243.

[64] D. Terentyev, D. Bacon, Y. Osetsky, Interaction of an edge dislocation with voids in a-iron modelled with different interatomic potentials, Journal of Physics: Condensed Matter 20 (2008) 445007.

[65] D. Terentyev, L. Malerba, Interaction of a screw dislocation with Cu-precipitates, nanovoids and $\mathrm{Cu}$-vacancy clusters in BCC iron, Journal of Nuclear Materials 421 (2012) 32-38.

[66] R.E. Stoller, S.J. Zinkle, On the relationship between uniaxial yield strength and resolved shear stress in polycrystalline materials, Journal of Nuclear Materials 283 (2000) 349-352.

[67] M.Y. Li, E. Werner, J.H. You, Fracture mechanical analysis of tungsten armor failure of a watercooled divertor target, Fusion Engineering and Design 89(11) (2014) 2716-2725.

[68] J.H. You, M. Li, K. Zhang, Structural lifetime assessment for the DEMO divertor targets: Designby-analysis approach and outstanding issues, Journal of Nuclear Materials submitted (2020). 